\title{
Enhanced Oxygen and Hydroxide Transport in a Cathode Interface by Efficient Antibacterial Property of a Silver Nanoparticle-Modified, Activated Carbon Cathode in Microbial Fuel Cells
}

Da Li,${ }^{\dagger}$ Youpeng Qu, ${ }^{\ddagger}$ Jia Liu, ${ }^{*},{ }^{\dagger}$ Guohong Liu, ${ }^{\dagger}$ Jie Zhang, ${ }^{\dagger}$ Yujie Feng ${ }^{*}, \dagger$

†State Key Laboratory of Urban Water Resource and Environment, Harbin Institute of Technology. No 73 Huanghe Road, Nangang District, Harbin 150090, China

${ }^{\ddagger}$ School of Life Science and Technology, Harbin Institute of Technology. No. 2

Yikuang Street, Nangang District, Harbin 150080, China

*Corresponding Author: E-mail: yujief@hit.edu.cn

*Corresponding Author: E-mail: jialiu@hit.edu.cn 
Table S1 BET analysis of AC and Ag/AC catalysts.

\begin{tabular}{lcc}
\hline \multicolumn{1}{c}{ Catalyst } & $\mathrm{AC}$ & $\mathrm{Ag} / \mathrm{AC}$ \\
\hline BET surface area $\left(\mathrm{m}^{2} \mathrm{~g}^{-1}\right)$ & 1841 & 1799 \\
Micropore area $\left(\mathrm{m}^{2} \mathrm{~g}^{-1}\right)$ & 518 & 551 \\
Micropore volume $\left(\mathrm{cm}^{3} \mathrm{~g}^{-1}\right)$ & 0.21 & 0.23 \\
Total pore volume $\left(\mathrm{cm}^{3} \mathrm{~g}^{-1}\right)$ & 0.93 & 0.90 \\
\hline
\end{tabular}

Table S2 Fitting results of Nyquist plot by equivalent circuit for the $\mathrm{AC}$ and $\mathrm{Ag} / \mathrm{AC}$ cathode

\begin{tabular}{lcc}
\hline \multicolumn{1}{c}{ Cathode } & $\mathrm{AC}$ & $\mathrm{Ag} / \mathrm{AC}$ \\
\hline$R_{\mathrm{ohm}}(\Omega)$ & 28.21 & 22.56 \\
$C_{\mathrm{dl}}\left(\times 10^{-6} \Omega^{-1} \mathrm{~s}^{\mathrm{N}} \mathrm{cm}^{-2}\right)$ & 1.264 & 0.5593 \\
$n_{\mathrm{df}}$ & 0.6108 & 0.6809 \\
$R_{\mathrm{d}}(\Omega)$ & 10.31 & 5.97 \\
$Z_{\mathrm{w}}\left(\Omega \mathrm{s}^{-1 / 2}\right)$ & 0.1497 & 0.4776 \\
$C_{\mathrm{ad}}\left(\times 10^{-4} \Omega^{-1} \mathrm{~s}^{\mathrm{N}} \mathrm{cm}^{-2}\right)$ & 6.86 & 7.921 \\
$n_{\mathrm{ad}}$ & 0.7925 & 0.7556 \\
$R_{\mathrm{ct}}(\Omega)$ & 6.88 & 5.95 \\
\hline
\end{tabular}




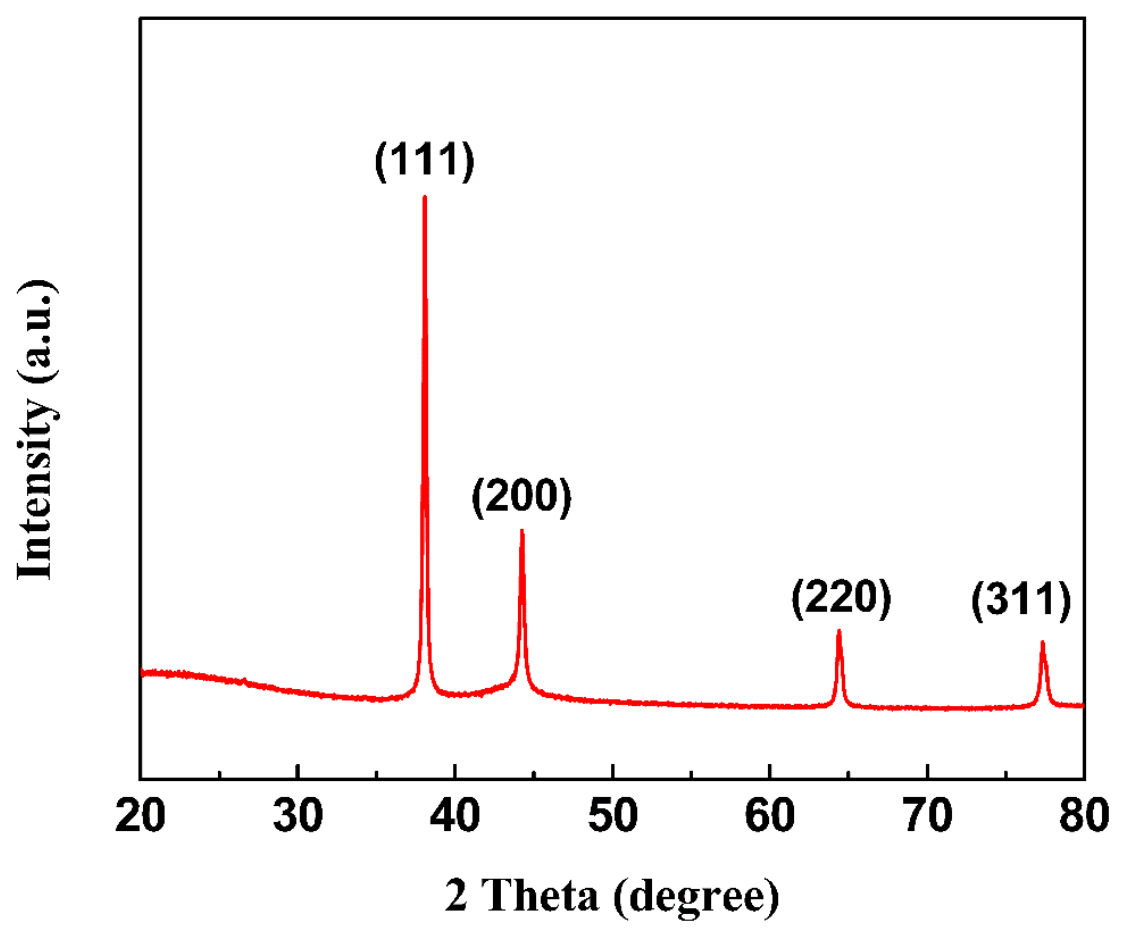

Figure S1. XRD patterns of $\mathrm{Ag} / \mathrm{AC}$ catalysts.

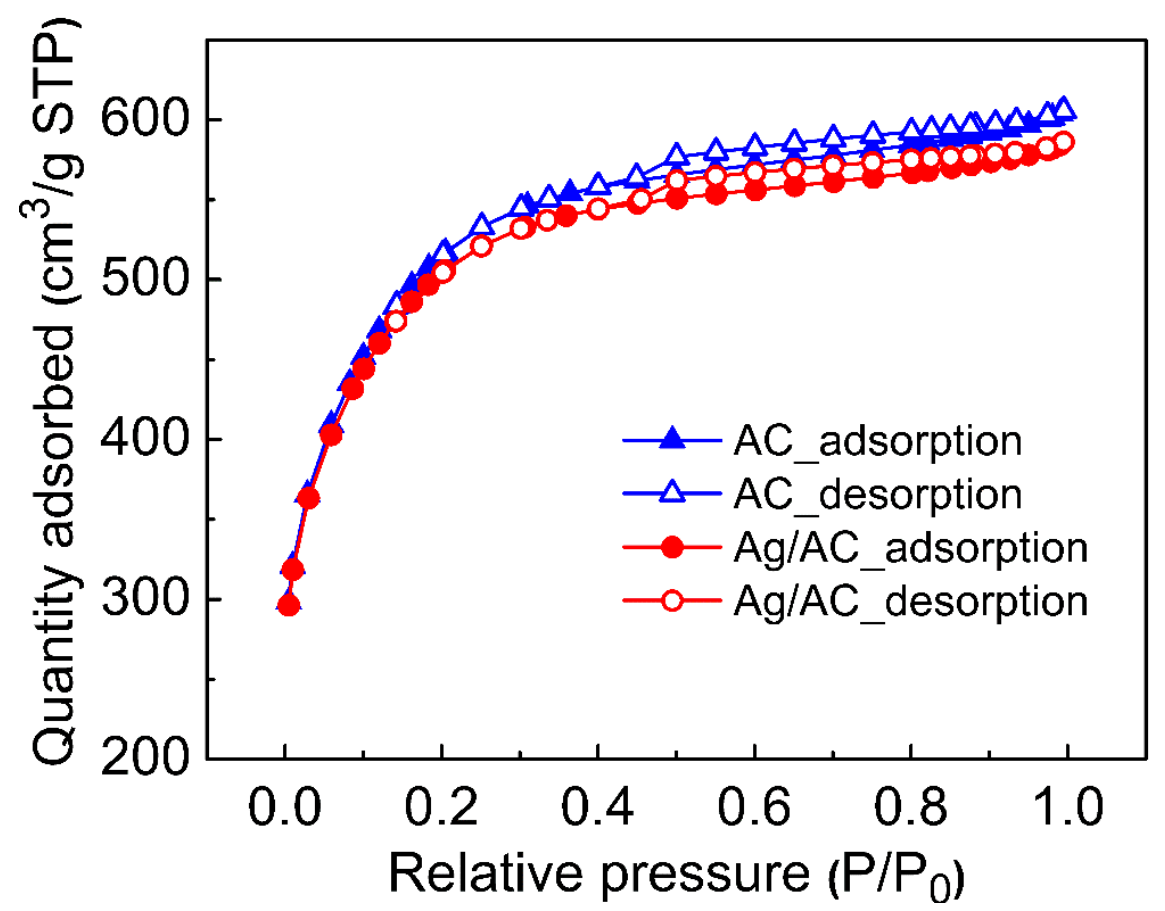

Figure S2. $\mathrm{N}_{2}$ adsorption (solid points)/desorption (hollow points) isotherms of AC and $\mathrm{Ag} / \mathrm{AC}$. 


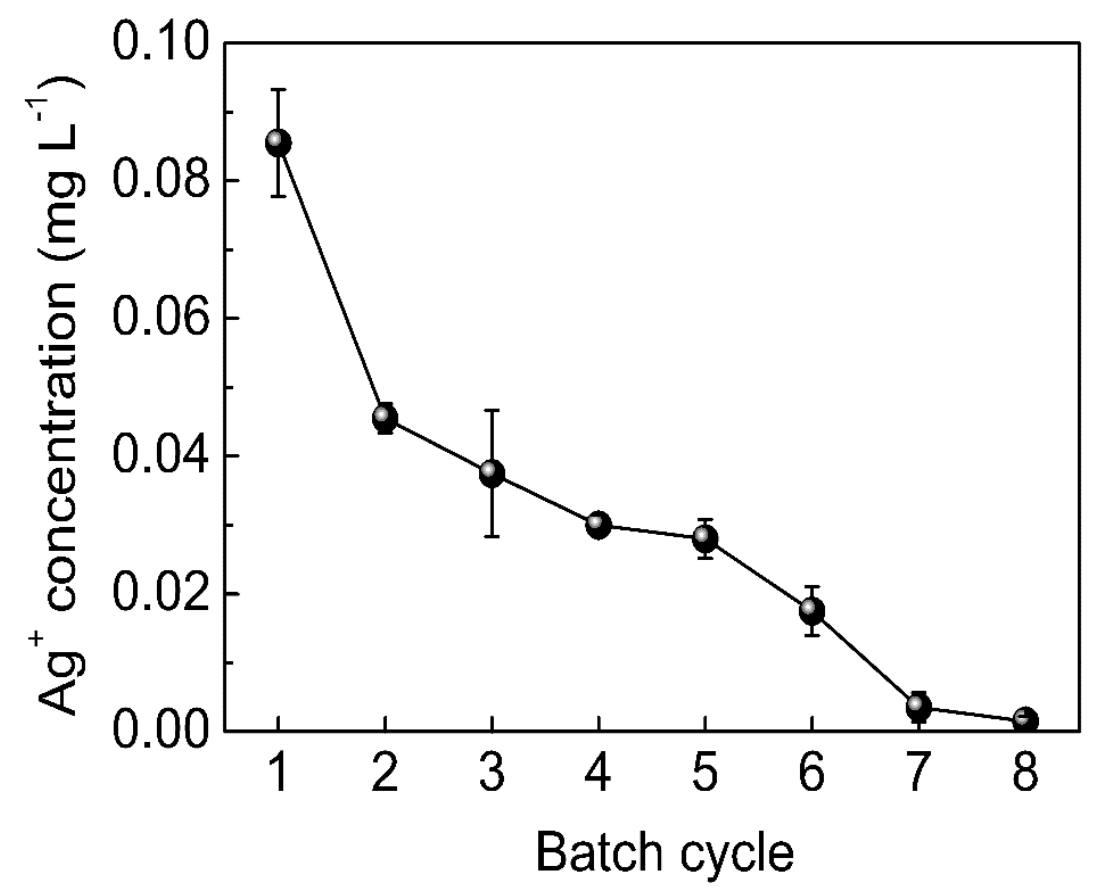

Figure S3. $\mathrm{Ag}^{+}$concentration in MFCs effluent with $\mathrm{Ag} / \mathrm{AC}$ cathodes.

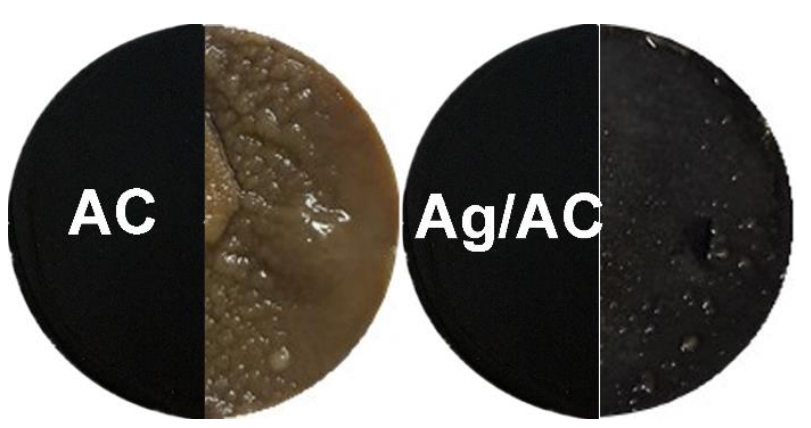

Figure S4. Photograph of $\mathrm{AC}$ and $\mathrm{Ag} / \mathrm{AC}$ cathode before (left) and after biofilm developed (right). 


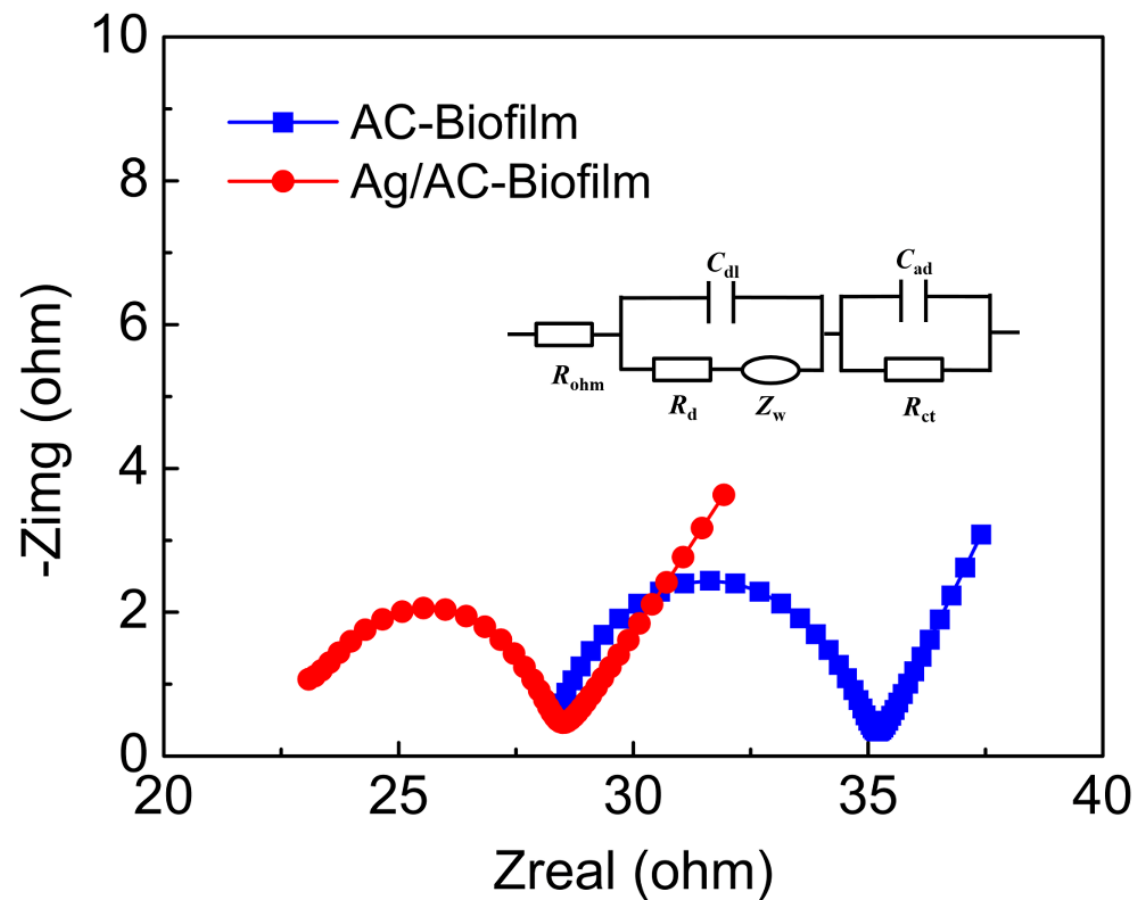

Figure S5. Nyquist plot of electrochemical impedance spectroscopy at $-0.1 \mathrm{~V}$ (versus $\mathrm{Ag} / \mathrm{AgCl}$ ) in $50 \mathrm{mM} \mathrm{PBS}$ for $\mathrm{AC}$ and $\mathrm{Ag} / \mathrm{AC}$ cathode after biofilm growth, the equivalent circuit was inserted in the graph. 